\title{
Desempenho agronômico e ganho genético pela seleção de pinhão-manso em três regiões do Brasil
}

\author{
Bruno Galvêas Laviola(1), Sergio Delmar dos Anjos e Silva( ${ }^{(2)}$, Ana Cristina Pinto Juhász ${ }^{(3)}$, \\ Rodrigo Barros Rocha ${ }^{(4)}$, Reriton Joabél Pires de Oliveira(2), Julio Cesar Albrecht ${ }^{(5)}$, \\ Alexandre Alonso Alves ${ }^{(1)}$ e Tatiana Barbosa Rosado(6)
}

\begin{abstract}
(1)Embrapa Agroenergia, Parque Estação Biológica (PqEB), W3 Norte (final), CEP 70770-901 Brasília, DF, Brasil. E-mail: bruno.laviola@embrapa.br, alexandre.alonso@embrapa.br ${ }^{(2)}$ Embrapa ClimaTemperado, Rodovia BR-392, Km 78, CEP96010-971 Pelotas, RS, Brasil.E-mail: sergio.anjos@embrapa.br, rerinton@yahoo.com.br ${ }^{(3)}$ Empresa de PesquisaAgropecuária de Minas Gerais, Centro Tecnológico do Triângulo Mineiro eAlto Paranaíba, RuaAfonso Rato, n 1.301,BairroMercês, CEP38060-040 Uberaba, MG,Brasil.E-mail:anacpj@yahoo.com.br

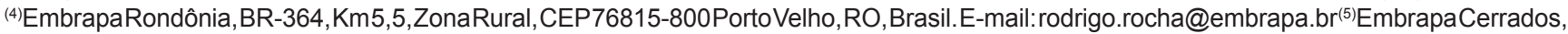
BR-020, Km 18, CEP 73310-970 Planaltina, DF, Brasil. E-mail: julio.albrecht@embrapa.br ${ }^{(6)}$ Universidade de Brasília (UnB), Faculdade UnB Planaltina, campus de Planaltina, área universitária 01, CEP 73345-010 Planaltina, DF, Brasil. E-mail: tatianarosado@unb.br
\end{abstract}

Resumo - O objetivo deste trabalho foi avaliar o desempenho agronômico e o ganho genético pela seleção de famílias de meio-irmãos de pinhão-manso, cultivado em três regiões do Brasil. A partir de seleção fenotípica prévia, foram instalados três testes de progênies, em 2008, nos municípios de Planaltina, DF, Nova Porteirinha, MG, e Pelotas, RS. Utilizou-se o delineamento de blocos ao acaso, com três repetições e cinco plantas por parcela. Como testemunha, foram utilizadas sementes, colhidas ao acaso, de uma população sem seleção. Houve interação significativa entre os efeitos de genótipos por ambientes. As estimativas dos componentes de variância e dos parâmetros genéticos indicaram que é possível obter ganhos com a seleção das melhores famílias, nos ambientes avaliados. Em cada ambiente, ao menos uma família foi selecionada com desempenho superior ao tratamento-controle. O ganho genético médio, obtido pela seleção massal nos três ambientes, foi de $72 \%$. Observou-se alto coeficiente de correlação entre os ambientes de Planaltina e Nova Porteirinha, quanto ao desempenho agronômico, o que não se repetiu no Município de Pelotas. A interação genótipo x ambiente deve ser considerada na recomendação de materiais genéticos de pinhão-manso para ambientes distintos.

Termos para indexação: Jatropha curcas, interação genótipo x ambiente, genética quantitativa, melhoramento de plantas.

\section{Agronomic performance and genetic gain by selection of physic nut in three Brazilian regions}

\begin{abstract}
The objective of this study was to evaluate the agronomic performance and genetic gain by the selection of half-sib families of physic nut grown in three Brazilian regions. Based on previous phenotypic selection, three progeny tests were performed, in 2008, in the municipalities of Planaltina, DF, Nova Porteirinha, MG, and Pelotas, RS. A randomized complete block design was used, with three replicates, and five plants per plot. Randomly collected seeds from a population without selection were used as control. There was a significant interaction between the effects of genotypes and environments. Estimates of variance components and genetic parameters indicated that it is possible to obtain genetic gains from selection of the best families in the evaluated environments. In each environment, at least one family was selected with a higher performance than the control treatment. Mass selection in the three environments provided $72 \%$ of genetic gains. The agronomic performance had a high correlation coefficient between the environments of Planaltina and Nova Porteirinha, which did not occur in Pelotas. Genotype x environment interaction should be considered in the recommendations of physic nut genetic material for different environments.
\end{abstract}

Index terms: Jatropha curcas, genotype x environment interaction, quantitative genetics, plant breeding.

\section{Introdução}

O pinhão-manso (Jatropha curcas L.) é considerado uma alternativa interessante para atender parte da demanda por óleo vegetal, promovido pelo Programa Nacional de Produção e Uso de Biodiesel (PNPB) (Durães et al., 2009, 2011). Trata-se de uma oleaginosa perene, com bom potencial produtivo de grãos e

Pesq. agropec. bras., Brasília, v.49, n.5, p.356-363, maio 2014

DOI: $10.1590 / \mathrm{S} 0100-204 \mathrm{X} 2014000500005$ 
de óleo adequado para a produção de biodiesel. Além disso, o pinhão-manso apresenta elevada adaptabilidade a diferentes regiões do Brasil (Laviola et al., 2013a). Contudo, a espécie encontra-se em fase de domesticação, e ainda não há cultivares e sistema de cultivo validados para as diferentes regiões produtoras no País. Assim, o desenvolvimento de cultivares é necessário para que a espécie se consolide como alternativa para a produção de biodiesel em futuro próximo (Durães et al., 2011; Laviola et al., 2013a).

A formação da população de melhoramento é uma das etapas mais importantes de um programa de melhoramento. Essa população pode ser formada por genitores previamente selecionados, que representem a diversidade genética da espécie (Bhering et al., 2011). A seleção a priori de genótipos divergentes, com alto desempenho agronômico, aumenta a chance de obtenção de ganhos com a seleção, a partir de combinações gênicas superiores obtidas com a hibridação direcionada (Cruz, 2005). A produtividade de grãos é uma das características mais importantes para seleção de plantas com maior rendimento de óleo, seguida - em menor proporção - do volume de copa e do teor de óleo nos grãos (Spinelli et al., 2010).

$\mathrm{O}$ teste de progênies em diferentes ambientes é bastante utilizado na seleção de plantas, uma vez que permite a seleção quanto a características de herança complexa, governadas por vários genes e influenciadas pelo ambiente, o que capitaliza os efeitos da interação genótipo $\mathrm{x}$ ambiente. Por este motivo, no desenvolvimento e recomendação de uma nova variedade de pinhão-manso, o desempenho das melhores progênies deve ser avaliado em diferentes ambientes (Bhering et al., 2011).

Os programas de melhoramento de pinhão-manso no Brasil e no mundo ainda se encontram em fase inicial, e pouco se conhece sobre a interação genótipos $\mathrm{x}$ ambientes da espécie. Portanto, é importante que os materiais sejam avaliados em diferentes regiões com potencial para produção (Laviola et al., 2010; Bahadur et al., 2013; Carels et al., 2013; Juhász et al., 2013). Neste sentido, a rede de pesquisa do projeto Pesquisa, Desenvolvimento e Inovação em Pinhão-Manso para a Produção de Biodiesel vem realizando ensaios em diferentes instituições de pesquisa, com o objetivo de selecionar plantas adaptadas a diferentes regiões do Brasil (Laviola et al., 2013a).
O objetivo deste trabalho foi avaliar o desempenho agronômico e o ganho genético com a seleção de famílias de meio-irmãos de pinhão-manso, cultivado em três regiões do Brasil.

\section{Material e Métodos}

Os testes de progênies foram instalados no Centro-Oeste, Sudeste e Sul do Brasil, em 2008, para a avaliação do desempenho de 18 famílias de meio-irmãos (FMIs), nos seguintes municípios: Planaltina, DF; Nova Porteirinha, MG; e Pelotas, RS (Tabela 1). Os ensaios foram instalados em fevereiro de 2008, em delineamento de blocos ao acaso, com três repetições e cinco plantas, dispostas em linha, por parcela útil. $\mathrm{O}$ espaçamento adotado foi de $4 \times 2 \mathrm{~m}$. Os ensaios foram implantados com mudas de aproximadamente 60 dias de cultivo. As práticas de manejo basearam-se em Dias et al. (2007), com adaptações de acordo com os resultados de pesquisa com pinhão-manso no Brasil e no mundo (Bahadur et al., 2013; Carels et al., 2013; Resende et al., 2013).

Como tratamento-controle, utilizou-se a progênie 801 , que representa o primeiro material genético de pinhão-manso comercializado no Brasil, pela Empresa Biojan, de Janaúba, MG (Tominaga et al., 2007). Os demais tratamentos consistiram das progênies 803 a 813 , obtidas por seleção massal (produção de grãos) em 2007, pela Embrapa Semiárido, em Petrolina, PE. Essas progênies formaram a população $C_{1}$ (Drumond et al., 2010). A progênie 802 (população $\mathrm{C}_{0}$ ) foi obtida a partir de uma mistura de sementes da população em que foram selecionadas as progênies da população $C_{1}$ que, por sua vez, também foi formada por mistura de procedências de coletas no Estado de Pernambuco. Além destas, foram utilizadas também as progênies numeradas de 814 a

Tabela 1. Características edafoclimáticas dos ambientes usados na avaliação das 18 famílias de meio-irmãos de pinhão-manso (Jatropha curcas).

\begin{tabular}{lccccc}
\hline Ambiente & \multicolumn{5}{c}{ Clima $^{(1)}$ TemperaturaUR médiaPrecipitação Altitude } \\
& & média $\left({ }^{\circ} \mathrm{C}\right)$ & $(\%)$ & média $(\mathrm{mm})$ & $(\mathrm{m})$ \\
\hline Planaltina, DF & $\mathrm{Aw}$ & 21 & 68 & 1.100 & 1.007 \\
Nova Porteirinha, MG & $\mathrm{Aw}$ & 23 & 52 & 650 & 518 \\
Pelotas, RS & $\mathrm{Cfa}$ & 18 & 80 & 1.100 & 60 \\
\hline
\end{tabular}

${ }^{(1)}$ Classificação climática de Köppen-Geiger. Aw, savana com inverno seco; Cfa, clima subtropical úmido.

Pesq. agropec. bras., Brasília, v.49, n.5, p.356-363, maio 2014 DOI: $10.1590 / \mathrm{S} 0100-204 X 2014000500005$ 
818, previamente selecionadas por seleção massal (produção de grãos) em Nova Porteirinha, MG (Juhász et al., 2010).

Avaliou-se a produtividade de grãos (11 a 12\% de umidade) no ano agrícola de 2012/2013, que correspondeu ao terceiro ano de produção do pinhão-manso. As parcelas foram avaliadas quanto à produção de grãos ( $\mathrm{kg}$ por parcela), posteriormente convertida em produtividade de grãos $\left(\mathrm{kg} \mathrm{ha}{ }^{-1}\right)$. Realizaram-se entre duas e quatro colheitas de frutos maduros. O número de colheitas variou conforme a região de avaliação.

A análise de variância foi realizada a $5 \%$ de probabilidade, de acordo com o modelo estatístico $Y_{i j k}=m+(B / A)_{j k}+G_{i}+A_{j}+G_{i j}+\varepsilon_{i j k}$, em que: $Y_{i j k}$ é a observação no k-ésimo bloco, avaliado no i-ésimo genótipo e j-ésimo ambiente; $m$ é a média geral do ensaio; (B/A $)_{\mathrm{jk}}$ é o efeito do bloco k, dentro do ambiente j; $\mathrm{G}_{\mathrm{i}}$ é o efeito do genótipo $\mathrm{i} ; \mathrm{A}_{\mathrm{j}}$ é o efeito do ambiente $\mathrm{j} ; \mathrm{GA}_{\mathrm{ij}}$ é o efeito da interação entre o genótipo i e o ambiente $j ; \mathcal{E}_{\mathrm{ijk}}$ é o erro aleatório, associado à observação ijk. Os efeitos de genótipos foram considerados fixos, e os de ambientes, aleatórios. O teste de Dunnett foi usado para comparar as médias dos genótipos selecionados com a do tratamento-controle, tendo-se utilizado o teste de Scott-Knott para agrupar médias semelhantes. Ambos os testes foram avaliados a 5\% de probabilidade.

Avaliações descritivas também foram feitas, tendo-se considerado o desempenho dos genótipos nos diferentes ambientes. Todos os procedimentos estatísticos foram realizados com auxílio da ferramenta computacional Genes (Cruz, 2013).

\section{Resultados e Discussão}

As progênies interagiram significativamente com os ambientes avaliados, quanto à produtividade de grãos $(p<0,01)$. As progênies selecionadas, portanto, apresentam desempenho diferente do previsto pelo modelo matemático da simples soma direta dos efeitos de genótipo, em um determinado ambiente, o que é comum na avaliação de caracteres quantitativos, principalmente os de maior complexidade, como a produtividade de grãos (Laviola et al., 2010; Ardelean et al., 2012; Augustin et al., 2012; Bose \& Subudhi, 2012; Revanappa et al., 2012). Assim, estudos mais detalhados sobre a interação genótipo $\mathrm{x}$ ambiente (GxA) são necessários, para que a interação possa ser interpretada e contornada, e para que não interfira negativamente na seleção de plantas.

As estimativas de parâmetros genéticos (Tabela 2) são importantes para direcionar o programa de melhoramento, pois auxiliam no processo seletivo e servem como referencial teórico para as recomendações dos materiais comerciais (Maia et al., 2009; Rosado et al., 2012).

O coeficiente de determinação genotípico foi considerado de alta magnitude (Laviola et al., 2011, 2012, 2013b; Bhering et al., 2012, 2013), o que indica a existência de variabilidade genética nas populações e permite ganhos com a seleção das melhores famílias nos diferentes ambientes. A razão entre os coeficientes de variação genético e ambiental $(\mathrm{CVg} / \mathrm{Cve})$, no entanto, foi de 0,97 . Essa razão deve ser maior que 1, para que haja condições favoráveis à seleção (Vencovsky, 1987).

O coeficiente de correlação intraclasse foi estimado em 0,42 , de magnitude mediana. Esse coeficiente representa a tendência de manutenção da superioridade fenotípica dos genótipos, nos diferentes ambientes avaliados e, quanto maior o coeficiente de correlação, menor a interferência da interação genótipo x ambiente na população. Quando se observam baixos valores do coeficiente de correlação intraclasse, há indício de interação genótipo $\mathrm{x}$ ambiente do tipo complexa, em que é indicada a avaliação dos materiais genéticos no maior número de ambientes possível, antes de se realizar uma recomendação segura para plantio (Sturion \& Resende, 2004).

Tabela 2. Estimativa de parâmetros genéticos e ambientais, e componentes da média de produtividade de grãos $\left(\mathrm{kg} \mathrm{ha}^{-1}\right)$, de famílias de meio-irmãos de pinhão-manso (Jatropha curcas), avaliadas em três ambientes.

\begin{tabular}{lc}
\hline Parâmetro & Estimativa \\
\hline Componente quadrático genotípico & 107.164 \\
Componente de variância GxA & 30.165 \\
Variância residual & 112.664 \\
Coeficiente de determinação genotípico & 82,22 \\
Correlação intraclasse $\left.{ }^{1}\right)$ & 42,86 \\
Coeficiente de variação genético (CVg) & 22,34 \\
Coeficiente de variação ambiental (Cve) & 22,91 \\
Razão CVg/Cve & 0,97 \\
Média geral (kg ha $\left.{ }^{-1}\right)$ & 1464,75 \\
Máximo $\left(\mathrm{kg} \mathrm{ha}^{-1}\right)$ & 2.592 \\
Mínimo $\left(\mathrm{kg} \mathrm{ha}^{-1}\right)$ & 356
\end{tabular}

${ }^{(1)} \mathrm{r}=\mathrm{Vg} /(\mathrm{Vg}+\mathrm{Vga}+\mathrm{Vres})$ 
A primeira parcela da interação GxA é denominada de interação simples, e não acarreta maiores problemas à seleção. A segunda, denominada de complexa ou cruzada, dificulta a seleção de genótipos de adaptação mais ampla (Maia et al., 2009). Neste trabalho, a magnitude do componente de variância GxA, em relação à variância genética (componente quadrático genotípico), tem reflexo direto sobre a magnitude da correlação intraclasse.

Em valores absolutos, a média geral do experimento foi menor na avaliação dos genótipos em Pelotas (Tabela 3). Este resultado era esperado, uma vez que o pinhão-manso é uma planta de clima tropical, com menor adaptação às temperaturas da região Sul do Brasil (Gurgel et al., 2011). Além disso, as progênies foram previamente selecionadas na Embrapa Cerrados e na Epamig, em locais em que as temperaturas médias eram de $21-23^{\circ} \mathrm{C}$. Os ensaios conduzidos em Planaltina e Janaúba também proporcionaram menores coeficientes de variação ambiental e maiores componentes quadráticos genotípicos da produção de grãos, em comparação ao ensaio em Pelotas. Esse resultado indica que os dois primeiros ambientes apresentam condição mais favorável ao progresso genético pela seleção (Tabela 3).

A produtividade do tratamento-controle (progênie 801) esteve entre as maiores, mas não diferiu da observada em algumas progênies selecionadas pela Embrapa e a Epamig (Tabela 4). Em Pelotas, no entanto, a progênie 804 apresentou desempenho superior às testemunhas. De modo geral, os resultados indicam que, em termos de desempenho médio, as progênies selecionadas não superaram a testemunha 801 .

As progênies da seleção massal, realizada pela Embrapa Semiárido (população $\mathrm{C}_{1}$ ), apresentaram média superior à progênie 802 (população inicial $\mathrm{C}_{0}$ ). Portanto, foi possível obter ganhos já nesta primeira geração de seleção, mesmo com o uso de seleção

Tabela 3. Parâmetros genéticos da produtividade de grãos de 18 famílias de meio-irmãos de pinhão-manso (Jatropha curcas), especificados por ambiente.

\begin{tabular}{lcccc}
\hline Ambiente & $\begin{array}{c}\text { Produtividade } \\
\left(\mathrm{kg} \mathrm{ha}^{-1}\right)\end{array}$ & $\begin{array}{c}\mathrm{CV} \\
(\%)\end{array}$ & $\mathrm{S}^{2} \mathrm{~g}$ & $\mathrm{~h}^{2}$ \\
\hline Planaltina, DF & 1.543 & 14,48 & 162.736 & 90,71 \\
Nova Porteirinha, MG & 1.522 & 19,85 & 171.080 & 84,90 \\
Pelotas, RS & 1.328 & 33,39 & 83.495 & 56,02 \\
\hline
\end{tabular}

$\mathrm{S}_{\mathrm{g}}^{2}$, variância genotípica; $\mathrm{h}^{2}$, herdabilidade. massal (seleção fenotípica), praticada quanto a uma característica de alta complexidade como a produção de grãos.

Os maiores ganhos fenotípicos realizados foram observados nos ambientes de Pelotas e Nova Porteirinha (Tabela 5). A população $\mathrm{C}_{0}$, possivelmente, adaptouse melhor em Planaltina, onde apresentou sua maior produtividade e a menor diferença, em comparação às progênies selecionadas. Como a produtividade de grãos é uma característica quantitativa, espera-se baixa eficiência da seleção massal. No entanto, a alta intensidade de seleção praticada (3\%) e a variabilidade existente na população $\mathrm{C}_{0}$ podem ter favorecido o sucesso da seleção massal.

De maneira geral, verificou-se que a seleção realizada pela Embrapa apresentou média superior à da maior parte da seleção realizada pela Epamig (Tabela 6). Aparentemente, a população $\mathrm{C}_{0}$, utilizada pela Epamig, apresentava menor desempenho agronômico do que a utilizada pela Embrapa.

Esses resultados ressaltam a importância de trabalhos iniciais de caracterização dos recursos genéticos e de estabelecimento e estruturação de populações de

Tabela 4. Produtividade média das progênies avaliadas nos diferentes ambientes ${ }^{(1)}$.

\begin{tabular}{lccc}
\hline Progênie & Planaltina, DF & Nova Porteirinha, MG & Pelotas, RS \\
\hline & & Tratamento controle & \\
801 & $1.828 \mathrm{a}$ & $1.764 \mathrm{a}$ & $923 \mathrm{a}$ \\
\hline & & População $\mathrm{C}_{0}$ \\
802 & $1.448 \mathrm{~b}$ & $1.056 \mathrm{~b}$ & $693 \mathrm{~b}$ \\
\hline & \multicolumn{3}{c}{ População $\mathrm{C}_{1}$} \\
803 & $1.905 \mathrm{a}$ & $1.965 \mathrm{a}$ & $1.465 \mathrm{ab}$ \\
804 & $1.867 \mathrm{ab}$ & $2.039 \mathrm{a}$ & $1.975 \mathrm{~S}$ \\
805 & $1.588 \mathrm{ab}$ & $2.017 \mathrm{a}$ & $1.578 \mathrm{a}$ \\
806 & $2.048 \mathrm{a}$ & $1.840 \mathrm{a}$ & $979 \mathrm{ab}$ \\
807 & $1.757 \mathrm{ab}$ & $1.726 \mathrm{a}$ & $1.552 \mathrm{ab}$ \\
808 & $1.890 \mathrm{a}$ & $1.997 \mathrm{a}$ & $1.226 \mathrm{ab}$ \\
809 & $1.644 \mathrm{ab}$ & $1.404 \mathrm{ab}$ & $1.625 \mathrm{a}$ \\
810 & $1.697 \mathrm{ab}$ & $1.915 \mathrm{a}$ & $1.674 \mathrm{a}$ \\
811 & $1.928 \mathrm{a}$ & $1.826 \mathrm{a}$ & $1.784 \mathrm{a}$ \\
812 & $1.963 \mathrm{a}$ & $1.742 \mathrm{a}$ & $1.474 \mathrm{ab}$ \\
813 & $1.081 \mathrm{~b}$ & $1.078 \mathrm{~b}$ & $1.447 \mathrm{ab}$ \\
814 & $1.110 \mathrm{~b}$ & $777 \mathrm{~b}$ & $1.672 \mathrm{a}$ \\
815 & $1.214 \mathrm{~b}$ & $1.165 \mathrm{~b}$ & $1.156 \mathrm{ab}$ \\
816 & $1.123 \mathrm{~b}$ & $1.186 \mathrm{ab}$ & $1.061 \mathrm{ab}$ \\
817 & $1.220 \mathrm{~b}$ & $1.186 \mathrm{ab}$ & $997 \mathrm{ab}$ \\
818 & $470 \mathrm{I}$ & $710 \mathrm{~b}$ & $619 \mathrm{ab}$ \\
\hline
\end{tabular}

${ }^{(1)}$ Médias das progênies, seguidas de letras iguais, não diferem entre si, pelo teste de Dunnett, a 5\% de probabilidade. As médias seguidas de S e I são respectivamente superiores e inferiores às testemunhas. 
melhoramento. A população-base para o melhoramento deve ser formada por genitores selecionados em bancos de germoplasma, que apresentem média alta quanto ao caráter de interesse e representem a diversidade genética da espécie (Bhering et al., 2011). A seleção inicial de genótipos divergentes superiores quanto à produção de grãos e óleo, aumenta a chance de seleção de combinações gênicas superiores, já nas primeiras gerações, em razão da concentração de alelos favoráveis (Laviola et al., 2010; Juhász et al., 2013).

$\mathrm{O}$ coeficiente de coincidência entre as progênies selecionadas com intensidade de seleção de aproximadamente 40\% (seleção das sete progênies de melhor desempenho) foi alto, entre as famílias selecionadas nos ambientes de Planaltina e Nova Porteirinha (Tabela 7). Porém, esse coeficiente foi muito baixo entre as progênies selecionadas em Planaltina e Pelotas, ambientes bem distintos. Entre os ambientes de Nova Porteirinha e Pelotas, o coeficiente de coincidência foi intermediário. Portanto, quanto menor a distância geográfica entre os ambientes, maior a coincidência na seleção dos melhores genótipos. No entanto, fatores como latitude, altitude, clima e solo também interferem nesse resultado.

Na Figura 1, o centro dos quadrantes representa a média do desempenho fenotípico no par de ambientes em avaliação. A análise gráfica permite inferir sobre o desempenho e a adaptação fenotípica dos genótipos avaliados em pares de ambientes. Portanto, os genótipos dispostos nos quadrantes 4 e 2 (Q4 e Q2) têm desempenho agronômico coincidente no par de ambientes considerados. Assim, ou são inferiores nos dois ambientes (Q4) ou são superiores em ambos (Q2). Os genótipos classificados nos quadrantes 1 e 3 (Q1 e Q3) são mais bem adaptados a um dos ambientes considerados.

Nos ambientes de Planaltina e Nova Porteirinha, com exceção da progênie 809 , todos os genótipos enquadraram-se em Q4 ou Q2, o que mostra baixa interação GxA entre esses dois locais (Figura 1). Assim, o coeficiente de correção do desempenho fenotípico nos ambientes foi consideravelmente alto $(0,88)$. Esses resultados são interessantes, pois evidenciam que genótipos avaliados em um desses ambientes tendem a apresentar bom desempenho também no outro ambiente. De forma distinta, nas avaliações que envolviam Pelotas (Figura 1), o coeficiente de correlação fenotípica foi apenas médio (aproximadamente 0,5), com genótipos com amplas e específicas adaptações a um determinado ambiente.

Independentemente do ambiente, apenas genótipos selecionados pela Embrapa foram classificados em Q2 (alto desempenho). Quanto aos genótipos selecionados pela Epamig, esperava-se, incialmente, que eles apresentassem, em Nova Porteirinha, desempenho melhor do que os selecionados pela Embrapa, já que foram selecionados nesse ambiente (Juhász et al., 2010). Porém, os materiais selecionados pela Embrapa - seleção realizada em Petrolina, PE (Drumond et al., 2010) - apresentaram superioridade fenotípica também nesse ambiente.

Tabela 5. Ganho fenotípico $(\mathrm{G})$, em razão da seleção massal, das dez melhores progênies da população $\mathrm{C}_{1}$, em comparação ao desempenho da população $\mathrm{C}_{0}$.

\begin{tabular}{|c|c|c|c|c|c|c|c|c|}
\hline \multirow[t]{2}{*}{ Progênie } & \multicolumn{2}{|c|}{ Planaltina, DF } & \multicolumn{2}{|c|}{ Nova Porteirinha, MG } & \multicolumn{2}{|c|}{ Pelotas, RS } & \multicolumn{2}{|c|}{ Média Geral } \\
\hline & Média & $\mathrm{G}(\%)$ & Média & $\mathrm{G}(\%)$ & Média & $\mathrm{G}(\%)$ & Média & $\mathrm{G}(\%)$ \\
\hline & \multicolumn{8}{|c|}{ População $\mathrm{C}_{0}$} \\
\hline \multirow[t]{2}{*}{802} & 1.449 & 0 & 1056 & 0 & 693 & 0 & 1066 & 0 \\
\hline & \multicolumn{8}{|c|}{ Seleção massal das dez melhores progênies da população $C_{1}$} \\
\hline 803 & 1.905 & 32 & 1965 & 86 & 1466 & 111 & 1779 & 67 \\
\hline 804 & 1.867 & 29 & 2039 & 93 & 1976 & 185 & 1961 & 84 \\
\hline 805 & 1.588 & 10 & 2017 & 91 & 1578 & 128 & 1728 & 62 \\
\hline 806 & 2.049 & 41 & 1841 & 74 & 979 & 41 & 1623 & 52 \\
\hline 807 & 1.757 & 21 & 1726 & 63 & 1552 & 124 & 1678 & 57 \\
\hline 808 & 1.891 & 31 & 1997 & 89 & 1226 & 77 & 1705 & 60 \\
\hline 809 & 1.644 & 13 & 1404 & 33 & 1625 & 135 & 1558 & 46 \\
\hline 810 & 1.698 & 17 & 1915 & 81 & 1675 & 142 & 1763 & 65 \\
\hline 811 & 1.928 & 33 & 1827 & 73 & 1785 & 158 & 1847 & 73 \\
\hline$\underline{812}$ & 1.963 & 35 & 1742 & 65 & 1475 & 113 & 1727 & 62 \\
\hline Média $C_{1}$ & 1.829 & 26 & 1.847 & 75 & 1.534 & 121 & 1.737 & 63 \\
\hline
\end{tabular}


No ensaio de competição, o desempenho do melhor genótipo (progênie 806) foi de $2.048 \mathrm{~kg} \mathrm{ha}^{-1}$ de grãos (Tabela 5), aos 36 meses de idade, obtido em Planaltina. Este resultado é inferior ao relatado por Drumond et al. (2010), para este mesmo genótipo, cultivado em condições irrigadas no Município de Santa Maria da Boa Vista, PE, em que os autores realizaram uma primeira avaliação do desempenho das progênies selecionadas por seleção massal, e observaram produtividade média de dez progênies de $3.294 \mathrm{~kg} \mathrm{ha}^{-1}$, aos 24 meses, com variação de $2.853 \mathrm{a}$ $3.542 \mathrm{~kg} \mathrm{ha}^{-1}$. Provavelmente, as condições do ambiente de seleção dos materiais, somadas ao complemento da irrigação, favoreceram a maior produtividade e a maior precocidade dos materiais.

O presente trabalho é um dos primeiros a avaliar o desempenho agronômico de um grupo de genótipos selecionados de pinhão-manso, em diferentes condições

Tabela 6. Agrupamento das famílias de meio-irmãos de pinhão-manso (Jatropha curcas) quanto à produtividade ${ }^{(1)}$.

\begin{tabular}{lccc}
\hline Progênie & Planaltina, DF & Nova Porteirinha, MG & Pelotas, RS \\
\hline 803 & $1.905 \mathrm{a}$ & $1.965 \mathrm{a}$ & $1.465 \mathrm{a}$ \\
804 & $1.867 \mathrm{a}$ & $2.039 \mathrm{a}$ & $1.975 \mathrm{a}$ \\
805 & $1.588 \mathrm{a}$ & $2.017 \mathrm{a}$ & $1.578 \mathrm{a}$ \\
806 & $2.048 \mathrm{a}$ & $1.840 \mathrm{a}$ & $979 \mathrm{~b}$ \\
807 & $1.757 \mathrm{a}$ & $1.726 \mathrm{a}$ & $1.552 \mathrm{a}$ \\
808 & $1.890 \mathrm{a}$ & $1.997 \mathrm{a}$ & $1.226 \mathrm{~b}$ \\
809 & $1.644 \mathrm{a}$ & $1.404 \mathrm{~b}$ & $1.625 \mathrm{a}$ \\
810 & $1.697 \mathrm{a}$ & $1.915 \mathrm{a}$ & $1.674 \mathrm{a}$ \\
811 & $1.928 \mathrm{a}$ & $1.826 \mathrm{a}$ & $1.784 \mathrm{a}$ \\
812 & $1.963 \mathrm{a}$ & $1.742 \mathrm{a}$ & $1.474 \mathrm{a}$ \\
813 & $1.081 \mathrm{~b}$ & $1.078 \mathrm{~b}$ & $1.447 \mathrm{a}$ \\
814 & $1.110 \mathrm{~b}$ & $777 \mathrm{~b}$ & $1.672 \mathrm{a}$ \\
815 & $1.214 \mathrm{~b}$ & $1.165 \mathrm{~b}$ & $1.156 \mathrm{~b}$ \\
816 & $1.123 \mathrm{~b}$ & $1.186 \mathrm{~b}$ & $1.061 \mathrm{~b}$ \\
817 & $1.220 \mathrm{~b}$ & $1.186 \mathrm{~b}$ & $997 \mathrm{~b}$ \\
818 & $470 \mathrm{c}$ & $710 \mathrm{~b}$ & $619 \mathrm{~b}$ \\
\hline
\end{tabular}

${ }^{(1)}$ Médias seguidas de letras iguais, nas colunas, constituem grupo estatisticamente homogêneo, pelo teste de Scott-Knott, a 5\% de probabilidade.

Tabela 7. Coeficiente de coincidência entre ambientes, da seleção massal das sete melhores famílias, quanto à produção de grãos.

\begin{tabular}{lccc}
\hline Ambiente & $\mathrm{n}$ & $\begin{array}{c}\mathrm{N}^{\mathrm{o}} \text { de } \\
\text { coincidências }\end{array}$ & $\begin{array}{c}\text { Coeficiente de } \\
\text { coincidência }\end{array}$ \\
\hline Planaltina, DF x Nova Porteirinha, MG & 18 & 5 & 0,7142 \\
Planaltina, DF x Pelotas, RS & 18 & 2 & 0,2857 \\
Nova Porteirinha, MG x Pelotas, RS & 18 & 4 & 0,5714 \\
\hline
\end{tabular}

ambientais (Juhász et al., 2013), e traz a primeira quantificação da interação GxA em pinhão-manso.
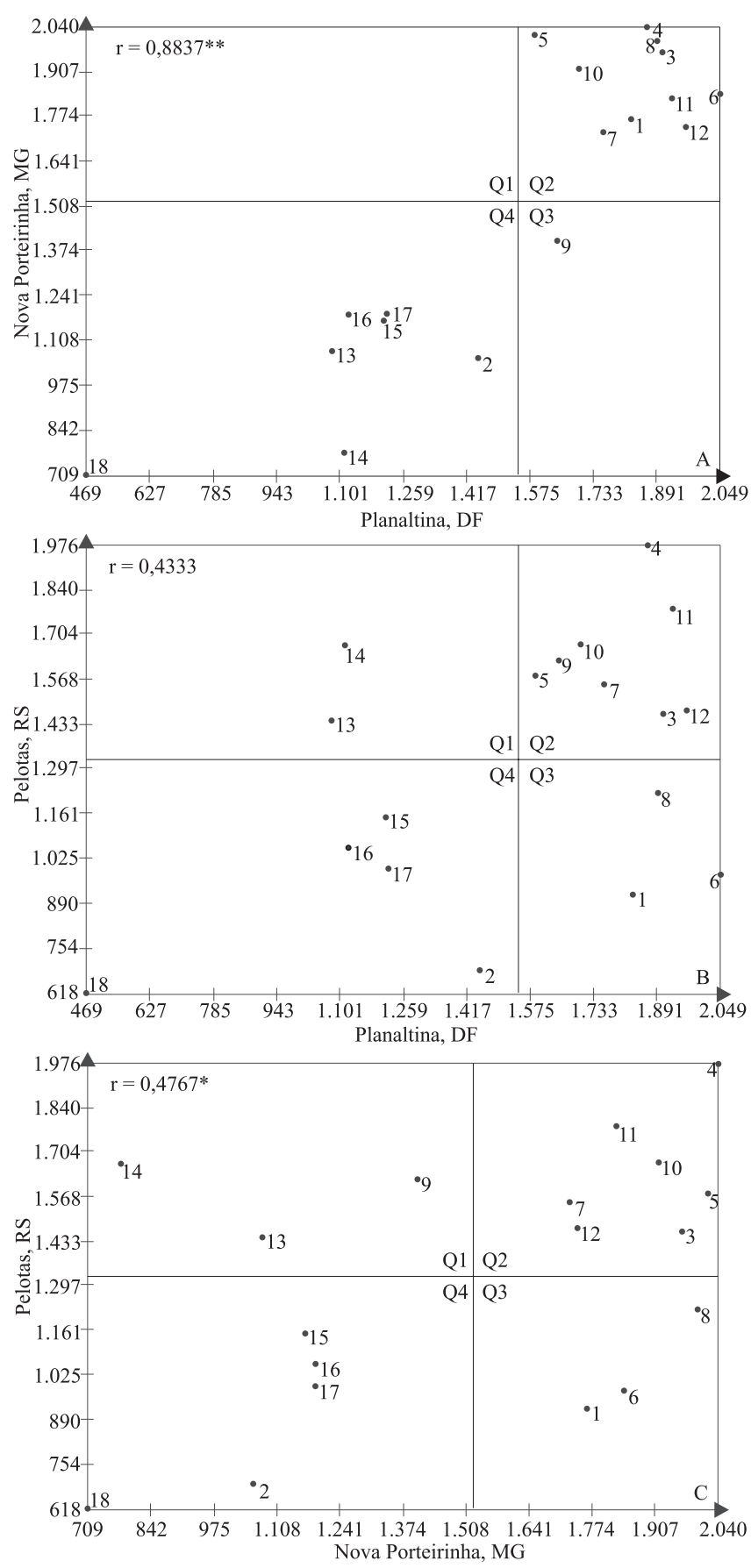

Figura 1. Correlação e dispersão gráfica do desempenho agronômico $\left(\mathrm{kg} \mathrm{ha}^{-1}\right)$ de 18 famílias de meio-irmãos de pinhão-manso (Jatropha curcas), em Planaltina, DF, Nova Porteirinha, MG, e Pelotas, RS. Numeração de 1 a 18 corresponde, respectivamente, às progênies de 801 a 818; r, correlação entre ambientes. 


\section{Conclusões}

1. Há interação genótipo $\mathrm{x}$ ambiente significativa quanto à produção de grãos, em progênies de meio-irmãos de pinhão-manso.

2. Os componentes de variância, bem como os parâmetros genéticos e ambientais, indicam a existência de variabilidade genética e de condições favoráveis à seleção das melhores famílias, nos diferentes ambientes.

\section{Agradecimentos}

Ao Ministério da Ciência, Tecnologia e Inovação, à Financiadora de Estudos e Projetos (Finep) e ao Conselho Nacional de Pesquisa e Desenvolvimento (CNPq), pelo apoio financeiro.

\section{Referências}

ARDELEAN, M.; CORDEA, M.; HAS, V.; BORS, A. G x E interaction on yield stability of five sweet corn hybrids grown under different agricultural systems. Notulae Botanicae Horti Agrobotanici Cluj-Napoca, v.40, p.290-292, 2012.

AUGUSTIN, L.; MILACH, S.; BISOGNIN, D.A.; SUZIN, M. Genotype $\mathrm{x}$ environment interaction of agronomic and processing quality traits in potato. Horticultura Brasileira, v.30, p.84-90, 2012. DOI: 10.1590/S0102-05362012000100015.

BAHADUR, B.; SUJATHA, M.; CARELS, N. Jatropha, challenges for a new energy crop. Volume 2: genetic improvement and biotechnology. New York: Springer Verlag, 2013. 614p. DOI: 10.1007/978-1-4614-4915-7.

BHERING, L.L.; BARRERA, C.F.; ORTEGA, D.; LAVIOLA, B.G.; ALVES, A.A.; ROSADO, T.B.; CRUZ, C.D. Differential response of Jatropha genotypes to different selection methods indicates that combined selection is more suited than other methods for rapid improvement of the species. Industrial Crops and Products, v.41, p.260-265, 2013. DOI: 10.1016/j.indcrop.2012.04.026.

BHERING, L.L.; CRUZ, C.D.; LAVIOLA, B.G. Biometria aplicada ao melhoramento de espécies alternativas para produção de biodiesel. In: CARDOSO, D.L.; LUZ, L.N. da; PEREIRA, T.N.S. (Ed.). Estratégias em melhoramento de plantas. Viçosa: Arka, 2011. p.89-119.

BHERING, L.L.; LAVIOLA, B.G.; SALGADO, C.C.; SANCHEZ, C.F.B.; ROSADO, T.B.; ALVES, A.A. Genetic gains in physic nut using selection indexes. Pesquisa Agropecuária Brasileira, v.47, p.402-408, 2012. DOI: 10.1590/S0100-204X2012000300012.

BOSE, L.K.; SUBUDHI, H.N. Genotype x environment interaction and stability analysis for grain yield and its components studies in dry season rice. International Journal of Agricultural and Statistical Sciences, v.8, p.659-666, 2012.

CARELS, N.; SUJATHA, M.; BAHADUR, B. Jatropha, challenges for a new energy crop. Volume 1: farming, economics and biofuel. New York: Springer Verlag, 2013. 599p. DOI: 10.1007/978-1-4614-4915-7_14.

CRUZ, C.D. Princípios de genética quantitativa. Viçosa: Ed. da UFV, 2005. 394p.

CRUZ, C.D. GENES - a software package for analysis in experimental statistics and quantitative genetics. Acta Scientiarum. Agronomy, v.35, p.271-276, 2013. DOI: 10.4025/ actasciagron.v35i3.21251.

DIAS, L.A. dos S.; LEME, L.P.; LAVIOLA, B.G.; PALLINI FILHO, A.; PEREIRA, O.L.; CARVALHO, M.; MANFIO, C.E.; SANTOS, A.S.; SOUSA, L.C.A.; OLIVEIRA, T.S.; DIAS, D.C.F.S. Cultivo de pinhão manso (Jatropha curcas L.) para produção de óleo combustível. Viçosa: Ed. da UFV, 2007. 40p.

DRUMOND, M.A.; SANTOS, C.A.F.; OLIVEIRA, V.R. de; MARTINS, J.C.; ANJOS, J.B. dos; EVANGELISTA, M.R.V. Desempenho agronômico de genótipos de pinhão manso no Semiárido pernambucano. Ciência Rural, v.40, p.44-47, 2010. DOI: $10.1590 / \mathrm{S} 0103-84782009005000229$.

DURÃES, F.O.M.; LAVIOLA, B.G.; ALVES, A.A. Potential and challenges in making physic nut (Jatropha curcas L.) a viable biofuel crop: the Brazilian perspective. CAB Reviews: Perspectives in Agriculture, Veterinary Science, Nutrition and Natural Resources, v.6, n.043, 2011. DOI: 10.1079/PAVSNNR20116043.

DURÃES, F.O.M.; LAVIOLA, B.G.; SUNDFELD, E.; MENDONCA, S.; BHERING, L.L. Pesquisa, desenvolvimento e inovação em pinhão-manso para produção de biocombustíveis. Brasília: Embrapa Agroenergia, 2009. 28p. (Embrapa Agroenergia. Documentos, 001)

GURGEL, F. de L.; LAVIOLA, B.G.; DA SILVA, D.M.; KOBAYASHI, A.K.; ROSADO, T.B. Phenology and biometry of physic nut in the Brazilian Savannah. Ciência e Agrotecnologia, v.35, p.1122-1131, 2011. DOI: 10.1590/ S1413-70542011000600012.

JUHÁSZ, A.C.P.; MORAIS, D. de L.B.; SOARES, B.O.; PIMENTA, S.; RABELlO, H. de O.; RESENDE, M.D.V. Parâmetros genéticos e ganho com a seleção para populações de pinhão-manso (Jatropha curcas). Pesquisa Florestal Brasileira, v.30, p.25-35, 2010. DOI: 10.4336/2010.pfb.61.25.

JUHÁSZ, A.C.P.; RESENDE, M.D.V. de; LAVIOLA, B.G.; COSTA, M.R. Melhoramento genético de Jatropha curcas: considerações e metodologias. In: RESENDE, J.C.F. de; LONDE, L.N.; NEVES, W. dos S. (Ed.). Pinhão-manso. Nova Porteirinha: Epamig, 2013. p.89-152.

LAVIOLA, B.G.; ALVES, A.A.; ROCHA, R.B.; DRUMOND, M.A. The importance of Jatropha for Brazil. In: CARELS, N.; SUJATHA, B.; BAHADUR, B. (Ed.). Jatropha, challenges for a new energy crop. Volume 1: farming, economics and biofuel. New York: Springer, 2013a. p.71-94.

LAVIOLA, B.G.; ALVES, A.A.; GURGEL, F. de D.; ROSADO, T.B.; ROCHA, R.B.; ALBRECHT, J.C. Estimates of genetic parameters for physic nut traits based in the germplasm two years evaluation. Ciencia Rural, v.42, p.429-435, 2012. DOI: 10.1590/ S0103-84782012000300008. 
LAVIOLA, B.G.; BHERING, L.L.; MENDONCA, S.; ROSADO, T.B.; ALBRECHT, J.C. Caracterização morfo-agronômica do banco de germoplasma de pinhao manso na fase jovem. Bioscience Journal, v.27, p.371-379, 2011.

LAVIOLA, B.G.; OLIVEIRA, A.M.C. e; BHERING, L.L.; ALVES, A.A.; ROCHA, R.B.; GOMES, B.E.L.; CRUZ, C.D. Estimates of repeatability coefficients and selection gains in Jatropha indicate that higher cumulative genetic gains can be obtained by relaxing the degree of certainty in predicting the best families. Industrial Crops and Products, v.51, p.70-76, 2013b. DOI: 10.1016/j. indcrop.2013.08.016.

LAVIOLA, B.G.; ROCHA, J.D.; KOBAYASHI, A.K.; ROSADO, T.B.; BHERING, L.L. Genetic improvement of Jatropha for biodiesel production. Ceiba, v.51, p.1-10, 2010. DOI: 10.5377/ ceiba.v51i1.640.

MAIA, M.C.C.; RESENDE, M.D.V. de; PAIVA, J.R. de; CAVALCANTE, J.J.V.; BARROS, L. de M. Seleção simultânea para produção, adaptabilidade e estabilidade genotípica em clones de cajueiro via modelos mistos. Pesquisa Agropecuária Tropical, v.39, p.43-50, 2009.

RESENDE, J.C.F. de; LONDE, L.N.; NEVES, W. dos S. Pinhão-manso. Nova Poerteirinha: Epamig, 2013. 524p.

REVANAPPA, S.B.; KAMANNAVAR, P.Y.; VIJAYKUMAR, A.G.; GANAJAXI, M.; GAJANAN, D.K.; ARUNKUMAR,
B.; SALIMATH, P.M. Genotype $\mathrm{x}$ environment interaction and stability analysis for grain yield in blackgram (Vigna mungo L.). Legume Research, v.35, p.56-58, 2012.

ROSADO, A.M.; ROSADO, T.B.; ALVES, A.A.; LAVIOLA, B.G.; BHERING, L.L. Seleção simultânea de clones de eucalipto de acordo com produtividade, estabilidade e adaptabilidade. Pesquisa Agropecuária Brasileira, v.47, p.964-971, 2012. DOI: 10.1590/ S0100-204X2012000700013.

SPINELLI, V.M.; ROCHA, R.B.; RAMALHO,A.R.; MARCOLAN, A.L.; VIEIRA JÚNIOR, J.R.; FERNANDES, C.F.; MILITÃO, J.S.L.T.; DIAS, L.A.S. Componentes primários e secundários do rendimento de óleo de pinhão-manso. Ciência Rural, v.40, p.1752-1758, 2010. DOI: 10.1590/S0103-84782010005000129.

STURION, J.A.; RESENDE, M.D.V. de. Eficiência do delineamento experimental e capacidade de teste no melhoramento genético da erva-mate (Ilex paraguariensis St. Hil.). Boletim de Pesquisa Florestal, v.50, p.3-10, 2004.

TOMINAGA, N.; KAKIDA, J.; YASUDA, E.K. Cultivo de pinhão-manso para produção de biodiesel. Viçosa: Centro de Produções Técnicas, 2007. 220p. (CPT. Série agroindústria).

VENCOVSKY, R. Herança quantitativa. In: PATERNIANI, E. (Ed.). Melhoramento e a produção de milho no Brasil. Piracicaba: Fundação Cargil, 1987. p.137-214.

Recebido em 17 de dezembro de 2013 e aprovado em 28 de abril de 2014 